\title{
Nutritional status in idiopathic scoliosis
}

\author{
J Durmala ${ }^{1 *}$, M Sosnowska², M Sosnowski $^{2}$ \\ From 8th International Conference on Conservative Management of Spinal Deformities and SOSORT 2011 \\ Annual Meeting \\ Barcelona, Spain. 19-21 May 2011
}

\section{Background}

A relatively high proportion of lean body habitus is an acknowledged feature of idiopathic scoliosis [1]. We aimed at evaluation of nutritional status in schoolchildren with idiopathic scoliosis managed in a single center of rehabilitation. Data from a homogeneous population regarding current national BMI reference is presented.

\section{Materials and methods}

303 children were included. There were 260 girls and 43 boys, aged $14.2 \pm 0.2$ and $14.1 \pm 0.4$ years, resp. In each girl or boy, the body height and mass was measured by using the standardized protocol. Individual BMI $(\mathrm{kg} / \mathrm{m} 2)$ was classified according to the established normal age- and gender-related range (Z-score) of limit for Polish children. The calculations were performed on basis of actually measured height (BMI), as well as after height correction (BMIcor). Data were compared with the BMI distribution in healthy children.

\section{Results}

The BMI values lower than 2SD Z-score and 1SD Z-score were found in $3.3 \%$ and $17.8 \%$. The BMI values higher than 2 SD and 1 SD were found in $0.3 \%$ and $7.9 \%$, resp. After correction for height, the proportions for low BMIcor were $5.0 \%$ and $24.0 \%$. There was none case of obesity after height-correction, and the proportion of overweight children reached $6.0 \%$. Compared to BMI in normal population, the frequency of low BMI or BMIcor in IS was found 3.05- or 4.2-times higher, resp. On contrary, the frequency of high BMI or BMIcor was 2.0 or 2.7-times lower, resp.

\section{Conclusions}

Almost one-third of children with IS are underweight, while obesity is a sporadic feature. Reasons of low nutritional status should be explained in each case.

${ }^{1}$ School of Health Care Katowice, Poland

Full list of author information is available at the end of the article
Author details

${ }^{1}$ School of Health Care Katowice, Poland. ${ }^{2}$ School of Medicine, Medical University of Silesia, Katowice, Poland.

Published: 27 January 2012

Reference

1. Burwell RG, Aujla RK, Grevitt MP, Dangerfield PH, Moulton A, Randell TL, Anderson SI: Pathogenesis of adolescent idiopathic scoliosis in girls- a double neuro-osseous theory involving disharmony between two nervous systems, somatic and autonomic expressed in the spine and trunk: possible dependency on sympathetic nervous system and hormones with implications for medical therapy. Scoliosis 2009, 4:24.

doi:10.1186/1748-7161-7-S1-022

Cite this article as: Durmala et al:: Nutritional status in idiopathic scoliosis. Scoliosis 2012 7(Suppl 1):O22.

\section{Submit your next manuscript to BioMed Central and take full advantage of: \\ - Convenient online submission \\ - Thorough peer review \\ - No space constraints or color figure charges \\ - Immediate publication on acceptance \\ - Inclusion in PubMed, CAS, Scopus and Google Scholar \\ - Research which is freely available for redistribution \\ Submit your manuscript at www.biomedcentral.com/submit}

